\title{
Analytic study of functional outcome of retrograde intramedullary nailing for distal femoral fractures in adults
}

\author{
Srujith Kommera*, Pradeep Reddy, Saba Khaleel
}

Department of Orthopaedics, Shadhan institute of medical sciences, Hyderabad, Telangana, India

Received: 24 April 2021

Revised: 31 May 2021

Accepted: 01 June 2021

\section{*Correspondence:}

Dr. Srujith Kommera,

Email: srujithk@yahoo.com

Copyright: (C) the author(s), publisher and licensee Medip Academy. This is an open-access article distributed under the terms of the Creative Commons Attribution Non-Commercial License, which permits unrestricted non-commercial use, distribution, and reproduction in any medium, provided the original work is properly cited.

\begin{abstract}
Background: The purpose of this Study was to evaluate the clinical and functional outcome of retrograde intramedullary nailing for distal femur fractures.

Methods: This 2 years observational study was done between December 2018 to January 2021, 60 patients with distal femoral fractures were surgically treated at our hospital using retrograde intramedullary nail. The patient was placed supine on fracture table with affected limb flexed to 60 degrees. Through a Transpatellar approach, the nail was introduced in retrograde method after serial reaming. Postoperatively knee range of motion was started immediately and weight bearing was progressed after signs of fracture union were noted on $\mathrm{x}$-rays. The outcome was evaluated for time taken for fracture union, complications and functional outcome with various types of fractures.

Results: All the fractures in the present study healed at an average of 13 weeks. However 25 to $40 \%$ of these patients underwent bone grafting primarily with reports of delayed union and non-union. Shortening occurred in two patients $(3.33 \%)$ did affect the final functional outcome. average range of motion is $120 \mathrm{deg}$. for all fractures, $119 \mathrm{deg}$. for extraarticular fractures and $118 \mathrm{deg}$. for intra-articular fractures. Infection rates are low (0\% to 8\%).

Conclusions: The study shows distal femoral fractures were common due to high velocity injuries, retrograde nailing is an excellent technique for management of distal femoral fractures as it promotes high rate of fracture union with less complications.
\end{abstract}

Keywords: Retrograde nailing, Distal femur fractures, Supracondylar approach, Mullers classification, Union, Functional outcome

\section{INTRODUCTION}

The distal femur is an area that is particularly vulnerable to the dangers of our modern lifestyles and high velocity methods of transportation. Fractures of the distal femur are complex injuries that can be difficult to manage. These serious injuries have the potential to produce significant long-term disability. Despite the advances in the techniques and the improvement in the surgical implant, treatment of distal femoral fractures remains a challenge in many situations..$^{2,3}$
The distal femur includes the distal $15 \mathrm{cms}$ of the femur including the distal femoral metaphysis (supracondylar) and the intercondylar area. The supracondylar area of the femur is defined as the zone between the femoral condyles and the junction of the metaphysis with the femoral shaft. This comprises the distal $9 \mathrm{~cm}$ of the femur, as measured from the articular surface. It is important to distinguish supracondylar fractures from low diaphyseal fractures of the distal femur because the methods of treatment and prognosis are considerably different1. Distal femoral fractures account for $7 \%$ of all femoral fractures, predominant in young males following high energy trauma. ${ }^{2,26}$ 
Over the past 30 years implants and techniques have improved. Intramedullary nailing concept was introduced by Küntscher and later it was modified. The intramedullary interlocking nail has emerged as the new treatment option in the management of distal femoral fractures. They obtain more "Biological" fixation than plates, are load sharing devices, offer greater soft tissue preservation, present less need for bone grafting, shown less chances of infection, provide good fixation in osteoporotic bone, have a $99 \%$ union rate and provide post-operative knee range of motion of nearly 130 degree. ${ }^{1,7,10}$

\section{Classification of supracondylar fractures}

Various treatment options are available for the management of these fractures. Earlier most of the distal femoral fractures were treated by non-operative method but the complications like angular deformity, joint incongruity, knee stiffness and delayed patient mobilization were common. ${ }^{4,22}$

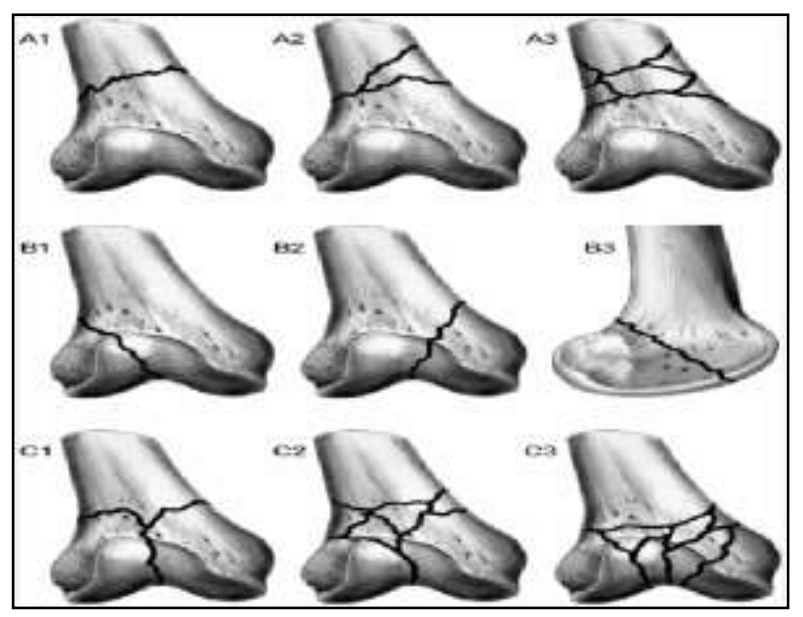

Figure 1: Muller's classification of supracondylar fracture femur.

\section{METHODS}

The present study is a case control study was conducted is in the Department of Orthopaedics, Shadan Institute Of Medical Sciences, Hyderabad, Telangana on patients with lower end femoral fractures during the period of 2 years from December 2018 to December 2020.

\section{Study design}

Two year prospective study.

\section{Source of data}

Patients operated by supracondylar intramedullary nailing for lower end femoral fractures in Department of Orthopaedics, Shadan Institute Of Medical Sciences, Hyderabad, Telangana were selected as study population.

\section{Sample size}

60 male and female patients with distal femoral fractures who were undergoing supracondylar intramedullary nailing were selected for the Study.

\section{Inclusion criteria}

All patients with age group above 18 years having distal femoral fractures including the supracondylar and supracondylar with intercondylar extension fractures with an indication for surgical management.

Multiple fractures in patients. Fractures occurring below hip implants or above knee implants with open notch design.

\section{Exclusion criteria}

Patients who are bedridden or non-ambulatory. Patients with severe life-threatening or other medical problems. Articular comminution. Fracture extension into isthmus. Patients managed conservatively. Pathological fractures.

Patients were operated under epidural/spinal / general anaesthesia. Patient was placed in supine position over a radiolucent operating table. Pneumatic tourniquet was applied. Then the limb was cleaned with detergent and cetrimide, scrubbed with povidine iodine $(7.5 \%)$, painted with povidine (five percent) and draping done. ${ }^{14}$



Figure 2: Entry point. ${ }^{13}$

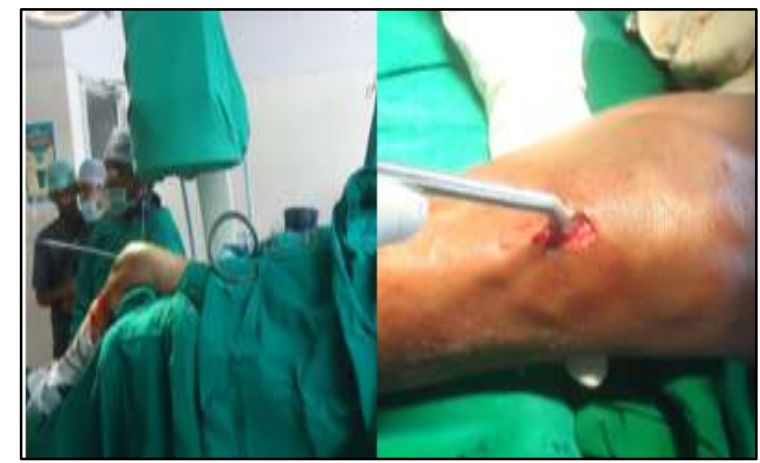

Figure 3: Position of patient and entry point with bone awl. 


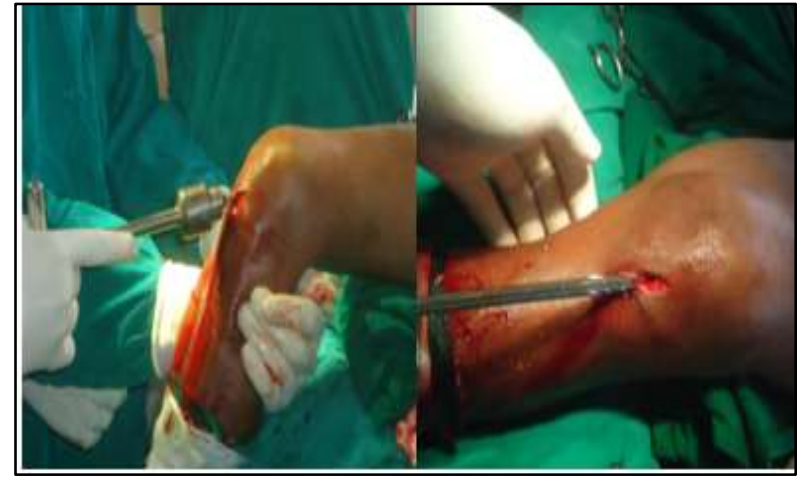

Figure 4: Passing guide wire and reaming.

\section{Incision and nail entry point ${ }^{15,19}$}

Use a vertical skin incision from the inferior pole of the patella to the tibial tuberosity. The point of entry of the nail lies centrally between the condyles in the sulcus intercondylaris, approximately $1 \mathrm{~cm}$ anterior to the insertion of the posterior cruciate ligament.

\section{Reaming}

The entry point was reamed $1.5 \mathrm{~mm}$ larger than the selected nail to avoid displacing the condyle when the nail is inserted. ${ }^{17,25}$

\section{Nail selection}

The size of the implant was based on the location and extent of the fracture. It was ensured that the size chosen will enable the nail to be locked securely into the proximal non-fractured zone. ${ }^{6,20}$

\section{Nail insertion}

A nail of the proper length and diameter was connected with the alignment rod placed through the guide bar. The nail was advanced until the distal end was countersunk two to five mm below the surface of the intercondylar notch and guide wire was removed. ${ }^{5,14}$

\section{Screws placement}

These supracondylar nails should be statically locked with at least two distal and two proximal screws. One proximal screw may be used if the nail has at least $10 \mathrm{~cm}$ of secure intramedullary purchase. The distal interlocking screws usually were placed first. 9,14

\section{Post-operative care}

Limb elevation over two pillows. Check X-ray of the operated femur (full length) including knee in both anteroposterior and lateral views. Intravenous antibiotics for five days postoperatively. To switch over to oral antibiotics by fifth post operative day. Analgesics if required given. Romovac Drain removed on the second post-operative day (if placed) and Wound inspection done on fifth post operative day. ${ }^{4,8}$

\section{Method of evaluation}

\section{Clinical assessment}

Sanders 40 point functional evaluation scale (Annexure I). ${ }^{10}$ Radiological Union: 1

\section{Follow up}

The cases were followed at four weeks, three months and sixth month by assessing Sanders 40 point functional evaluation scale. ${ }^{10}$

\section{Statistical analysis}

The data analysis was done for a period of three months as per Sanders 40 point functional evaluation scale10 using rates, ratios and percentages of different outcomes which were computed and compiled.

Results were analyased using Mcrosoft excel and presented in number and percentages.

\section{RESULTS}

This series consisted of 60 cases of a supracondylar and supracondylar with intercondylar extension fractures of the femur treated surgically by internal fixation with supracondylar intramedullary interlocking nail. Following observations were made from the data collected.

\section{Type of fracture}

Out of the 60 fractures, majority were extra-articular fractures. The extra-articular fractures constituted $75 \%$ of the fractures. Among them $40 \%$ were A1, $21.7 \%$ were A2 and $13.3 \%$ were A3 fractures. $25 \%$ were intra-articular fractures. Among them were $\mathrm{C} 1$ were $13.33 \%$ and $\mathrm{C} 2$ fractures were $11.7 \%$.

Table 1: Type of fracture.

\begin{tabular}{|lll|}
\hline AO Type & Number & Percentage \\
\hline A1 & 24 & 40 \\
\hline A2 & 13 & 21.7 \\
\hline A3 & 08 & 13.3 \\
\hline C1 & 08 & 13.3 \\
\hline C2 & 07 & 11.7 \\
Total & 60 & 100 \\
\hline
\end{tabular}

\section{Duration of surgery}

In 12 cases $(20 \%)$ the duration was less than one hour, in 38 cases $(63.3 \%)$ the duration was 1.0 to 1.5 hours and in ten cases $(16.7 \%)$ it was 1.5 to 2.0 hours. Operative time averaged 75 minutes for all fractures, 74 minutes for extra- 
articular fractures and 75 minutes for intra-articular fractures.

\section{Time taken for radiological union}

Average time to fracture union was 13 weeks (ranging from 10 to 18 weeks). 24 cases $(40 \%)$ took 10 to 12 weeks time to radiological union. 18 cases $(30 \%)$ took between 12 to 14 weeks time to radiological union. 12 cases $(20 \%)$ took between 14-16 weeks. There were six delayed unions (10\%) which took 16-18 weeks. None of the patients required bone grafting.

Table 2: Time taken for radiological union.

\begin{tabular}{|c|c|c|}
\hline Time (Weeks) & Number & Percentage \\
\hline 10 to 12 & 24 & 40 \\
\hline 12 to 14 & 18 & 30 \\
\hline 14 to 16 & 12 & 20 \\
\hline 16 to 18 & 06 & 10 \\
\hline Total & 60 & 100 \\
\hline
\end{tabular}

\section{Complications $^{9,12,23}$}

In the present study complications included anterior knee pain in six patients $(10 \%)$. Two patient had shortening $(>1.5 \mathrm{~cm})$ and. Three patients had knee stiffness and in four patients there was Intraoperative difficulty in reduction of fragments. There were no superficial infection, non-union and implant failures.

Table 3: Complications.

\begin{tabular}{|lll|}
\hline Complications & Number & Percentage \\
\hline Anterior knee pain & 06 & 10.00 \\
\hline Knee stiffness & 03 & 5 \\
\hline $\begin{array}{l}\text { Shortening (more than } \\
\text { 1.5 cm) }\end{array}$ & 02 & 3.3 \\
\hline $\begin{array}{l}\text { Difficulty in reduction of } \\
\text { fragments }\end{array}$ & 04 & 6.67 \\
\hline
\end{tabular}

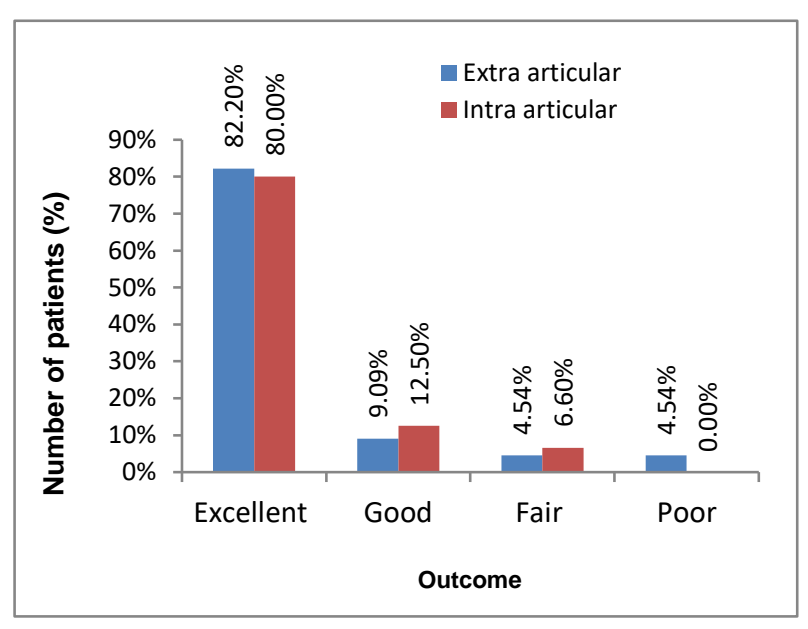

Figure 5: Assessment of outcome according to AO type of fractures.
Assessment of outcome according to AO type of fractures $^{20,21}$

On further critical analysis, it was found that type A extraarticular fractures had $(82.2 \%)$ excellent results $(9.09 \%)$ good, (4.54\%) fair, $(4.54 \%)$ had poor results as compared to type $\mathrm{C}$ intra-articular fractures, which had $80 \%$ excellent, $13.3 \%$ good and $6.7 \%$ fair results.

\section{Clinical pictures}

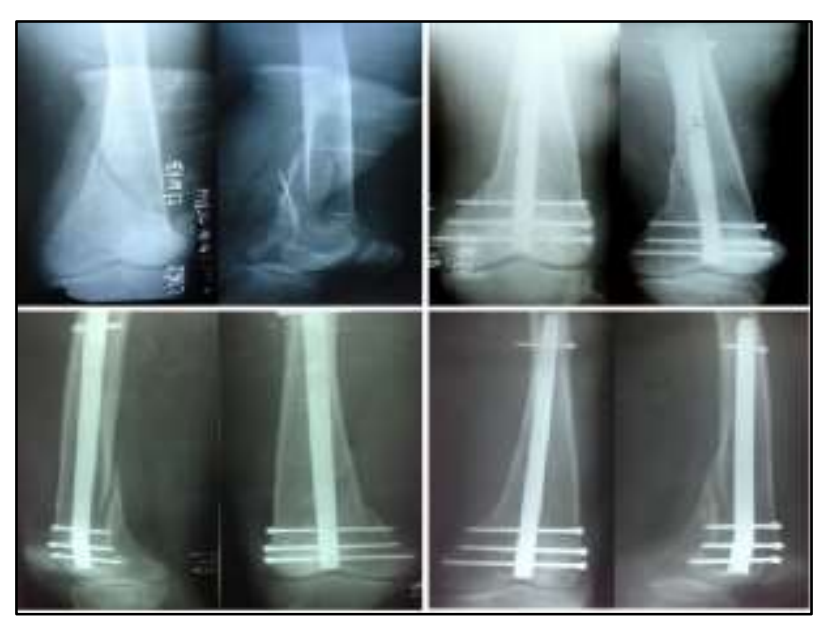

Figure 6: Case 1.

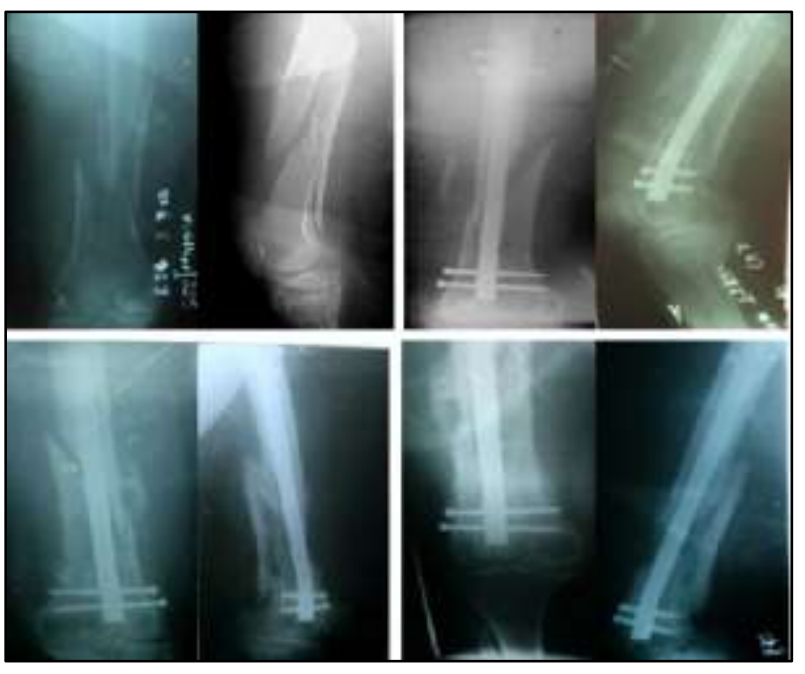

Figure 7: Case 2.

\section{DISCUSSION}

There has been no uniform reporting of the results of treatment of supracondylar and supracondylar with intercondylar extension femur fractures. It is difficult to compare the results of different reported series in literature, because of differences in demographic characteristics and differing fracture characteristics and is further complicated by the use of different classification systems and functional rating systems. 


\section{Comparison of mechanism of injury and fracture characteristics $^{26}$}

Percentage of compound fractures was comparable with studies of few authors. There were 12 cases $(20 \%)$ in the present study. Six were Gustilo type I and Four were type II and two were grade IIIA. Thorough irrigation and debridement was carried out for these cases. After debridement, immediate definitive internal fixation with supracondylar nailing was done. According to experienced fracture surgeons any delay in fixation increases the technical difficulty of the procedure and contributes to patient morbidity.

\section{Comparison of Muller's classification ${ }^{7}$}

Percentages of intra-articular fractures were more or less similar to that of Gellman et al and Lucas SM et al. This study had $25 \%$ of intra-articular fractures (type C) while there were $75 \%$ extra-articular (type A) fractures. There was no type B and C3 fractures included in the present study.

\section{Comparison of blood loss, operative time and union rate between different studies ${ }^{24,25}$}

The present study depicts that supracondylar nail has markedly decreased blood loss and operative time associated with treatment of supracondylar and supracondylar with intercondylar extension femoral fractures. Average estimated blood loss was $100 \mathrm{ml}$. In 48 $(80 \%)$ cases, blood loss was less than $100 \mathrm{ml}$ and in 12 $(20 \%)$ cases it was more than $100 \mathrm{ml}$, all of them are compound fractures. None of the patients required blood transfusion.

Furthermore, average operative time is lesser as compared to similar studies. In four cases $(6.7 \%)$, the duration of surgery was around two hours. There were associated compound (open) fractures which required thorough debridement. Operative time averaged 75 minutes for all fractures.

\section{Comparison of functional outcomes with different rating scales}

Using this scale, there were $82.2 \%$ excellent results in type A extra-articular fractures. The excellent results of type A fractures can be attributed to simple, stable fracture configuration, no intra-articular involvement and vigorous post-operative rehabilitation. This study compared to a previous study (using same scale) showed better scores. The previous study included type C3 fractures. These fractures were excluded from this study.

\section{CONCLUSION}

Supracondylar intramedullary nailing in supracondylar and supracondylar with intercondylar extension of femoral fractures makes "biological osteosynthesis" possible in these difficult and complex fractures with less operative time, minimal soft tissue stripping, minimal blood loss, decreased need for bone grafting and reasonably rigid fixation in osteoporotic bones. It provides predictably reproducible good functional results with low morbidity and good healing rates as well as satisfactory mobility in AO type A and C distal femoral fractures. This safe, successful, effective and reliable technique should find a place in the armamentarium of every orthopaedic surgeon dealing with distal femoral fractures that initially requires attention to details of operative technique.

Funding: No funding sources

Conflict of interest: None declared

Ethical approval: The study was approved by the institutional ethics committee

\section{REFERENCES}

1. Coon MS, Best BJ. Distal Femur Fractures. In: StatPearls [Internet]. Treasure Island (FL): StatPearls Publishing. 2021.

2. Prasanna A, Jeyaraman M, Chaudhari K, Ajay SS, Sabarish K, et al. Prospective Study on Functional Outcome of Retrograde Femoral Nailing in Distal Third Femoral Fractures. J ClinExpOrthop. 2019;5(2):65.

3. Verma R, Kumar K, Sidhu V, Saraf A. An Overview of Cases of Fracture Distal Femur: A Hospital Based Study. Int J Med Res Prof. 2018;4(6):319-22.

4. Kim JW, Oh CW, Oh JK, Park KH, Kim HJ, Kim TS et al. Treatment of infra-isthmal femoral fracture with an intramedullary nail: Is retrograde nailing a better option than antegrade nailing? Arch Orthop Trauma Surg. 2018;138(9):1241-7.

5. Jillala SR, Ahmed SMW, Shruthi A, Gajul R, Katikitala A, Rakesh K. A Comparative Study of Supracondylar Nail Versus Locking Compression Plate in Distal Femur Fractures. Ann. Int. Med. Den. Res. 2017;3(4):OR35-41.

6. Steinberg EL, Elis J, Steinberg Y, Salai M, Ben-Tov T. A double-plating approach to distal femur fracture: A clinical study. Injury. 2017;48(10):22605.

7. Shrihari LK, Mannual S, Sapan DS. A clinical study of distal femoral fractures treated by retrograde femoral nailing-biological and biomechanical advantages with review of literature. Int $\mathbf{J}$ Ortho Traumatol Surg Sci. 2016;2:371-7.

8. Surulivel VJ, Ganesan GR, Rajasekharan R. Dynamic condylar screw versus supracondylar nail in the management of supracondylar fracture distal femur. Int Surg J. 2015;2(3):373-6.

9. Demirta AS, Azboy I, Gem M, Alemdar C. Comparison of retrograde intramedullary nailing and bridge plating in the treatment of extra-articular fractures of distal femur. Acta Orthop Traumatol Turc. 2014;48(5):521-6.

10. Court-Brown CM, Clement ND, Duckworth AD, Aitken S, Biant LC, McQueen MM. The spectrum of 
fractures in the elderly. Bone and Joint Journal. 2014;96-B:366-72.

11. Demirtaş A, Azboy I, Özkul E, Gem M, Alemdar C. Comparison of retrograde intramedullary nailing and bridge plating in the treatment of extra-articular fractures of the distal femur. Acta Orthop Traumatol Turc. 2014;48(5):521-6.

12. Biber R, Stedtfeld HW, Bail HJ. The TargonPH(®) nail for distal femoral fracture fixation in disabled children. A report of three cases. OrthopTraumatolSurg Res. 2014;100(6):699-702.

13. Gupta SKV, Govindappa CVS, Yalamanchili RK. Outcome of retrograde intramedullary nailing and locking compression plating of distal femoral fractures in adults. OA Orthopaedics. 2013;1(3):23.

14. Kim J, Kang SB, Nam K, Rhee SH, Won JW, Han HS. Retrograde intramedullary nailing for distal femur fracture with osteoporosis. Clin Orthop Surg. 2012;4(4):307-12.

15. Kulkarni SG, Varshneya A, Kulkarni GS, Kulkarni MG, Kulkarni VS, Kulkarni RM. Antegrade Interlocking nailing for distal femoral fractures. J Ortho Surg. 2012;20(1):48-54.

16. Hierholzerc, vonRüden C, Pötzel T, Woltmann A, Bühren V. out come analysis of retrograde nailing and less invasive stabilization system in the distal femoral fractures, retrospective analysis" .Indian journal of orthopaedics. 2011;45(3):243-50.

17. Streubel PN, Ricci WM, Wong A, Gardner MJ. Mortality after distal femur fractures in elderly patients. ClinOrthopRelat Res. 2011;469:1188-96.

18. Bucholz RW, Heckman JD. Rockwood and Greens fractures in adults.th Ed. London: Lippincott Williams and Wilkins. 2010.

19. Henderson CE, Lujan T, Bottlang M, Fitzpatrick DC, Madey SM, Marsh JL. Stabilization of distal femur fractures with intramedullary nails and locking plates: differences in callus formation. Iowa Orthop J. 2010;30:61-8.

20. El Moumni M, Schraven P, ten Duis HJ, Wendt K. Persistent knee complaints after retrograde unreamed nailing of femoral shaft fractures. Acta Orthop Belg. 2010;76:219-25.

21. Suzuki T, Smith WR, Stahel PF, Morgan SJ, Baron AJ, Hak DJ. Technical problems and complications in the removal of the less invasive stabilization system. J Orthop Trauma. 2010;24:369-73.

22. Neubauer T, Ritter E, Potschka T. Retrograde nailing of femoral fractures. Acta Chir Orthop Traumatol Cech. 2008;75:158-66.

23. Salem KH, Maier D, Keppler P, Kinzl L, Gebhard F. Limb malalignment and functional outcome after antegrade versus retrograde intramedullary nailing in distal femoral fractures. J Trauma. 2006;61:375-81.

24. Patel K, Kapoor A, Daveshwar R, Golwala P. Percutaneous intramedullary supracondylar nailing for fractures of distal femur. The Medical journal of Malaysia. 2004;59:206-7.

25. Mosheiff R. Treatment of type C supraconylar femoral fractures using a retrograde supracondylar nail., JBJS. 2001;83:290.

26. Gellman GD, Paiement HD, Green, Coughlin RR. Treatment of Supracondylar Femoral Fractures with a Retrograde Intramedullary nail. Clin Orthop Relat Res. 1996;332:90-7.

Cite this article as: Kommera $\mathrm{S}$, Reddy $\mathrm{P}$, Khaleel S. Analytic study of functional outcome of retrograde intramedullary nailing for distal femoral fractures in adults. Int J Res Orthop 2021;7:824-9. 